\title{
Comparison of Two Electromagnetic Navigation Systems For CT-Guided Punctures: A Phantom Study
}

\section{Elektromagnetische Navigationssysteme im Vergleich: CT-gezielte Punktionen an einem Phantom}

Authors

Affiliation
D. Putzer, D. Arco, B. Schamberger, F. Schanda, J. Mahlknecht, G. Widmann, P. Schullian, W. Jaschke, R. Bale

Department of Radiology, Innsbruck Medical University, Innsbruck, Austria
Key words

- electromagnetic navigation system

- CT guided punctures

needle guidance system

- biopsy

- CT

- interventional procedures

received $\quad 7.10 .2015$

accepted $\quad 1.2 .2016$

Bibliography

Dol http://dx.doi.org/

10.1055/s-0042-103691

Published online: 13.4.2016

Fortschr Röntgenstr 2016; 188: 470-478 @ Georg Thieme

Verlag KG Stuttgart · New York . ISSN 1438-9029

\section{Correspondence}

Ao. Univ. Prof. Dr. Reto Bale,

MD

Department of Radiology

Section of Interventional

Oncology - Microinvasive

Therapy (SIP) Medical University Innsbruck

Anichstraße 35

6020 Innsbruck

Austria

Tel.: ++ 43/5 12/5 04-8 0540

Fax: ++ 43/5 12/5 04-26034

reto.bale@-med.ac.at

\section{Zusammenfassung}

$\nabla$

Ziel: Die Studie dient dem Vergleich der Zielgenauigkeit und Zuverlässigkeit von 2 elektromagnetischen Navigationssystemen für manuell gesteuerte Punktionen an einem Phantom.

Material und Methoden: CT-Datensätze eines mit Gelatine gefüllten Plexiglas-Phantoms wurden mit 1,3 und $5 \mathrm{~mm}$ Schichtdicke erfasst. Nach PunktPaar-Registrierung des Phantoms wurden insgesamt 480 stereotaktisch navigierte, manuelle Nadelinsertionen mit 2 verschiedenen Navigationssystemen durchgeführt (Medtronic Stealth Station: AXIEM; Philips: PercuNav). Ein Kontroll-CT diente zur Messung der Abweichungen zwischen der geplanten und tatsächlichen Nadelposition.

Ergebnisse: Unter Verwendung von Philips PercuNav waren die euklidischen Abstände 4,42 $\pm 1,33 \mathrm{~mm}, 4,26 \pm 1,32 \mathrm{~mm}$ und $4,46 \pm 1,56 \mathrm{~mm}$ bei einer Schichtdicke von 1, 3 und $5 \mathrm{~mm}$. Die mittleren seitlichen Positionsfehler waren 3,84 $\pm 1,59 \mathrm{~mm}, 3,84 \pm 1,43 \mathrm{~mm}$ und $3,81 \pm 1,71 \mathrm{~mm}$. Unter Verwendung der Medtronic Stealth-Station AXIEM waren die euklidischen Abstände 3,86 \pm $2,28 \mathrm{~mm}, 3,74 \mathrm{~mm}$ und $\pm 2,14,81 \pm 2,07 \mathrm{~mm}$ bei einer Schichtdicke von 1, 3 und $5 \mathrm{~mm}$. Die mitt-

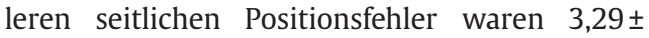
$1,52 \mathrm{~mm}, 3,16 \pm 1,52 \mathrm{~mm}$ und $3,93 \pm 1,68 \mathrm{~mm}$.

Schlussfolgerung: Beide elektromagnetischen Navigationsgeräte lieferten ausgezeichnete Ergebnisse in Bezug auf die Genauigkeit. Die Medtronic Stealth-Station AXIEM ermöglichte genauere Ergebnisse im Vergleich zur Philips PercuNav, bei Durchführung der CT mit $3 \mathrm{~mm}$ Schichtdicke. Die Tatsache, dass elektromagnetische Navigationssysteme keinen direkten Sichtkontakt zwischen Nadel und Feldgenerator erfordern, ist ein potentieller Vorteil. Im Hinblick auf einen möglichen Einfluss von metallischen Objekten auf die Genauigkeit der Navigation sind weitere Studien zur Beurteilung notwendig. Im klinischen Alltag

\section{Abstract \\ $\nabla$}

Purpose: We compared the targeting accuracy and reliability of two different electromagnetic navigation systems for manually guided punctures in a phantom.

Materials and Methods: CT data sets of a gelatin filled plexiglass phantom were acquired with 1,3 , and $5 \mathrm{~mm}$ slice thickness. After paired-point registration of the phantom, a total of 480 navigated stereotactic needle insertions were performed manually using electromagnetic guidance with two different navigation systems (Medtronic Stealth Station: AxiEM; Philips: PercuNav). A control CT was obtained to measure the target positioning error between the planned and actual needle trajectory.

Results: Using the Philips PercuNav, the accomplished Euclidean distances were $4.42 \pm 1.33 \mathrm{~mm}$, $4.26 \pm 1.32 \mathrm{~mm}$, and $4.46 \pm 1.56 \mathrm{~mm}$ at a slice thickness of 1,3 , and $5 \mathrm{~mm}$, respectively. The mean lateral positional errors were $3.84 \pm 1.59 \mathrm{~mm}$, $3.84 \pm 1.43 \mathrm{~mm}$, and $3.81 \pm 1.71 \mathrm{~mm}$, respectively. Using the Medtronic Stealth Station AxiEM, the Euclidean distances were $3.86 \pm 2.28 \mathrm{~mm}, 3.74 \pm$ $2.1 \mathrm{~mm}$, and $4.81 \pm 2.07 \mathrm{~mm}$ at a slice thickness of 1,3 , and $5 \mathrm{~mm}$, respectively. The mean lateral positional errors were $3.29 \pm 1.52 \mathrm{~mm}, 3.16 \pm 1.52 \mathrm{~mm}$, and $3.93 \pm 1.68 \mathrm{~mm}$, respectively.

Conclusion: Both electromagnetic navigation devices showed excellent results regarding puncture accuracy in a phantom model. The Medtronic Stealth Station AxiEM provided more accurate results in comparison to the Philips PercuNav for CT with $3 \mathrm{~mm}$ slice thickness. One potential benefit of electromagnetic navigation devices is the absence of visual contact between the instrument and the sensor system. Due to possible interference with metal objects, incorrect position sensing may occur. In contrast to the phantom study, patient movement including respiration has to be compensated for in the clinical setting. 
müssen im Rahmen der Navigation Bewegungsartefakte und Atemartefakte bedacht werden.

Kernaussagen:

> Kommerziell verfügbare, elektromagnetische Navigationssysteme haben das Potential, den therapeutischen Einsatzbereich von CT gezielten Punktionen zu erweitern, wenn man die Genauigkeit der Nadelplatzierung mit den Planungsdatensätzen in unterschiedlichen Schichtdicken vergleicht.
Key points:

> Commercially available electromagnetic navigation systems have the potential to improve the therapeutic range for CT guided percutaneous procedures by comparing the needle placement accuracy on the basis of planning CT data sets with different slice thickness.

Citation Format:

- Putzer D, Arco D, Schamberger B et al. Comparison of Two Electromagnetic Navigation Systems For CT-Guided Punctures: A Phantom Study. Fortschr Röntgenstr 2016; 188: 470-478

\section{Introduction}

\section{$\nabla$}

CT-guided punctures are an integral part of diagnostic and therapeutic interventions in daily clinical practice, with an increasing application range, such as liver biopsy and stereotactic radio frequency ablation [1,2]. In order to achieve highly accurate results, CT-guided procedures require multiple scans, resulting in a significant radiation burden to the patient. Image-guided navigation systems are a promising tool to improve accuracy and reduce radiation exposure during punctures.

Precise positioning of instruments and placement of puncture needles are operator dependent, and real-time tracking systems assist in handling of instruments and needles. Different guidance and navigation systems have been introduced for more accurate and reproducible puncture results. Several electromagnetic or optical tracking and navigation devices have been developed $[3,4]$. Both methods have shown satisfying results in orthopedic surgery, and electromagnetic tracking proved to be equivalent to optical tracking, with both systems producing sub-degree accuracy [5]. Both systems have also shown feasible and accurate results in neurosurgery [6]. Although optical tracking has been described as a highly accurate and reliable method, it does require a constant line of sight during navigation. Electromagnetic tracking, however, is susceptible to distortions of the electromagnetic field but still poses an appealing method for improving navigation accuracy and simplifying the workflow. Therefore, it has been proposed in several applications, such as augmentation of laparoscopic images [7].

Navigation with electromagnetic tracking for interventional radiologic procedures enables accurate positioning of therapeutic devices without a direct line of sight between the instrument and the localizer. In order to compare system reliability and reproducibility, we aimed to analyze the accuracy of electromagnetically guided punctures in a phantom model using two different guidance systems for manually performed needle insertion. The study was performed to assess possible differences of two electromagnetic navigation systems regarding the influence of slice thickness on positioning accuracy. The optimization of CT slice thickness for electromagnetically guided biopsies bears the potential for reducing the radiation burden in clinical practice, potentially decreasing the need for repeated control scans. In order to evaluate possible deviations, the Euclidean distance and the lateral positional error between the actual and the planned needle trajectory were measured at the target point by image fusion of the planning CT and the control CT. The study was performed to evaluate whether two commercially available electromagnetic navigation systems have the potential to improve the therapeutic range for CT-guided percutaneous procedures by comparing the needle placement accuracy on the basis of planning CT data sets with different slice thicknesses.

\section{Material and Methods}

\section{Phantom}

The phantom used for the tests was developed by our group for accuracy analysis purposes and was previously described [8]. In brief, it consists of a plexiglass box $(220 \times 150 \times 175 \mathrm{~mm}$, 0 Fig. 1) with 10 spatially distributed spacers and conically shaped targets having aluminum tips. The cover of the cube contains 20 openings for needle insertions that are each $8 \mathrm{~mm}$ in diameter. The cover is locked in 4 different positions, which allows for up to 80 different settings for puncture. Overall, 10 reference points are fixed to the surface of the cube, containing a metal sphere for registration purposes. The phantom is filled with gelatin, mimicking soft tissue properties, and is mounted in a fixed orientation on a solid plate.

\section{Navigation System \\ Hardware}

The PercuNav (Philips Healthcare, Toronto, Ontario, Canada) and the AxiEM Medtronic Stealth Station (Medtronic, Louisville, Kentucky, USA) navigation systems were used for the punctures.

Both systems consist of a workstation which is linked to a tool connection unit for the navigation instruments. They are equipped with field generators, consisting of different transmitter coil arrays and a navigation needle which is inserted into coaxial puncture needles. The Philips PercuNav needle is a coaxial needle measuring $232 \times 1.88 \mathrm{~mm}$ (13G). The AxiEM biopsy needle measures $230 \times 1.2 \mathrm{~mm}(16 \mathrm{G})$. A patient tracker is rigidly fixed to the structure that is tracked. Apart from that, the functionalities of the hardware components are comparable.

\section{Software}

In both systems, calculation of the geometrical transformation was based on a paired-point registration procedure. After calibration of the probes, the virtual planning data sets are registered to the real phantom by indicating ten reference points on the phantom and selecting the corresponding points on the data set. The systems recognize the instruments by their characteristic field strength, as reference needle, dynamic reference frame, and puncture probes contain tiny coils.

\section{Procedure}

80 punctures each at three different slice thicknesses were performed with both navigation systems, for a total of 480 punctures. The steps of the procedures were identical for both systems. For planning of the puncture trajectories, the phantom was scanned in the CT (Siemens Somatom Sensation Open, Siemens AG, Erlangen, Germany) with a gantry opening of $82 \mathrm{~cm}$. CT scans $(120 \mathrm{kV}, 200 \mathrm{mAs}, 24 \times 12$ collimation, 1.0 pitch, $0.5 \mathrm{sec}$. rotation time, and an FOV of $42.9 \mathrm{~cm}$ ) were performed with 1,3 , and 

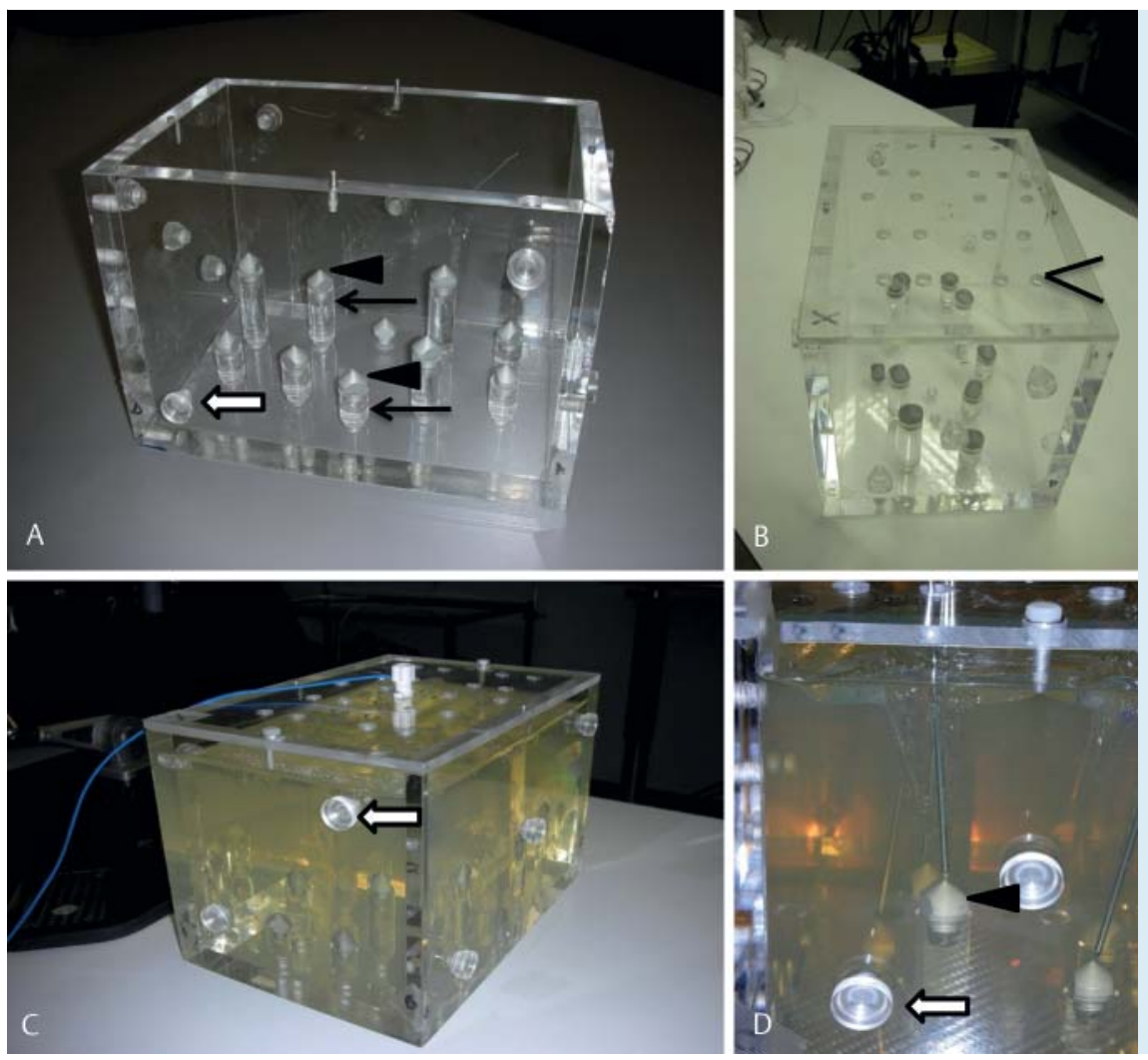

Fig. 1 The plexiglass phantom A, B contains the markers for planning, registration, and puncture and is filled with gelatin C, D. To place the targets, the phantom is equipped with 10 spatially distributed spacers $(\leftarrow)$. The conically shaped targets, which have an aluminum tip, are placed on top of the spacers ( $\rightarrow$ ). The cover of the box contains 20 openings for needle insertions (<). 10 reference points containing a metal sphere are fixed to the surface of the cube for registration purposes (translucent arrow).

Abb. 1 Das Plexiglas-Phantom A, B enthält die Marker für die Planung, Registrierung und Punktion und ist mit Gelatine C, D gefüllt. Um die Ziele zu platzieren, wird das Phantom mit 10 räumlich verteilten Abstandshaltern $(\leftarrow)$ ausgestattet. Die mit einer Aluminiumspitze ausgestatteten, konisch geformte Ziele sind am freien Ende der Abstandshalter angebracht ( $\triangleleft$ ). Der Deckel der Box enthält 20 Öffnungen für Nadel Insertionen (<). Zehn Referenzpunkte, die eine Metallkugel beinhalten, sind auf der Oberfläche des Kubus zu Registrierungszwecken fixiert (durchsichtiger Pfeil).

$5 \mathrm{~mm}$ slice thickness, resulting in 12 planning data sets, all of which were stored to the PACS (Picture Achieving and Communication System).

The patient tracker was attached to the phantom. The field generator was positioned in close proximity to the phantom. The CT images were automatically reconstructed to a three-dimensional data set. The phantom was displayed and showed the three major planes and a three-dimensional reconstruction. Ten reference points were defined for registration. These points were randomly mounted to the phantom in a three-dimensional distribution around the volume of interest. A paired-point registration procedure was performed using ten metal spheres for reference. The maximum tolerated registration errors were 0.9 . The puncture pathways were planned in accordance with the geometry and position of the conically shaped targets as visualized in the major planes and the reconstruction. The operator was able to switch between longitudinal and perpendicular cuts along the planned path during the planning phase. Using the planning software, the entrance and target points were defined on the multiplanar reconstructed CT data set. The tips of the cones were identified on the $3 \mathrm{D}$ data set and defined as target points. The center point of the access hole next to the cone of interest was defined as the entrance point. After finishing the registration procedure, the phantom was movable within the magnetic field.

During puncture, the actual position of the needle and the puncture pathway were displayed together with three crosses, showing the entry point, the tip of the needle, and the tip of the cone, which allowed for optimal guidance of the needle by superimposition of the three crosses ( $\bullet$ Fig. 2, 3). In case of misplacement of the needle, a circle surrounding the crosshairs gave information about the actual distance between the tip of the needle and the cone. After placement of 10 needles, CT with $1 \mathrm{~mm}$ slice thickness was performed to verify the position of the needles $(120 \mathrm{kV}$, $120 \mathrm{mAs}, 0.6$ collimation, 0.8 pitch, $0.5 \mathrm{sec}$. rotation time).

\section{Evaluation}

The CT data set was transferred to the Medtronic Stealth Station Treon using the hospital's own intranet. The $\mathrm{x}, \mathrm{y}$, and $\mathrm{z}$ coordinates of the planned entry point, the actual entry point, the tip of the cone (target), and the tip of the needle were recorded ( $\bullet$ Fig. 4). The deviations between the planned puncture trajectory and the actual needle path were evaluated based on the verification CT data set. The Euclidean distance and the lateral positional error between the tip of the needle and the tip of the cone were calculated. The Euclidean distance is defined as the distance between two arbitrary points in the three-dimensional space, while the lateral positional error is defined as the distance between a point and a line. Therefore, the Euclidean distance was calculated using the Pythagorean theorem. The Euclidean distance in this setting was given as the hypotenuse of a rectangular triangle. Considering the $\mathrm{x}, \mathrm{y}$, and $\mathrm{z}$ coordinates for point " $\mathrm{Z}$ " as the tip of the cone ( $\mathrm{Zx}, \mathrm{Zy}, \mathrm{Zz}$ ) and point "N" as the tip of the needle (Nx, Ny, Nz), the Euclidean distance was calculated using the

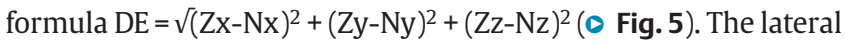
positional error was calculated using the formula $\mathrm{DN}=\sqrt{2} \mathrm{x}\left(\mathrm{de}^{2} \mathrm{~g}^{2}\right.$ $\left.+\mathrm{f}^{2} \mathrm{~g}^{2}+\mathrm{de}^{2} \mathrm{f}^{2}\right)-\left(d \mathrm{de}^{4}+\mathrm{f}^{4}+\mathrm{g}^{4}\right) / 2 \mathrm{f}$. (० Fig. 6). The "f" resembled the real course of the biopsy, while the "g" represented the planned trajectory. The distance "f" was the actual path between the needle entry point and the tip of the needle. The distance " $g$ " was the planned path between the entry point and the target point. The path " $\mathrm{d}_{\mathrm{e}}$ " was the Euclidian distance between the target point and the actual position of the tip of the needle. 


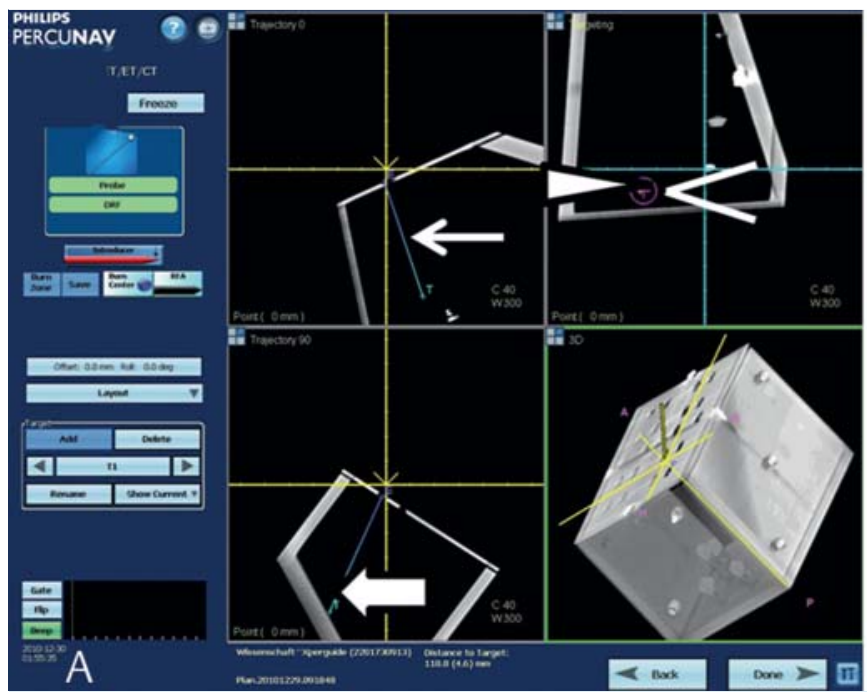

Fig. 2 Screenshot of Philips PercuNav during puncture. The plexiglass box and the targets are displayed in a multiplanar view, representing the three major planes and $3 \mathrm{D}$ volume rendering on the lower right side of each screenshot. On the left side of the screen, the icons allow the applicator to navigate within the dataset and to perform measurements. On the screenshot on the left $\mathbf{A}$, the actual position of the probe tip is depicted by the yellow crosshairs. The planned trajectory corresponds to the blue arrow $(\leftarrow)$. Three crosses are visible, which correspond to the needle tip $(\triangleleft)$, the entry point $(<)$, and the target point (translucent arrow). The three crosses should be superimposed to reach the optimal position for the puncture. The screenshot on the right $\mathbf{B}$ displays the ideal alignment of the probe with the planned puncture path.

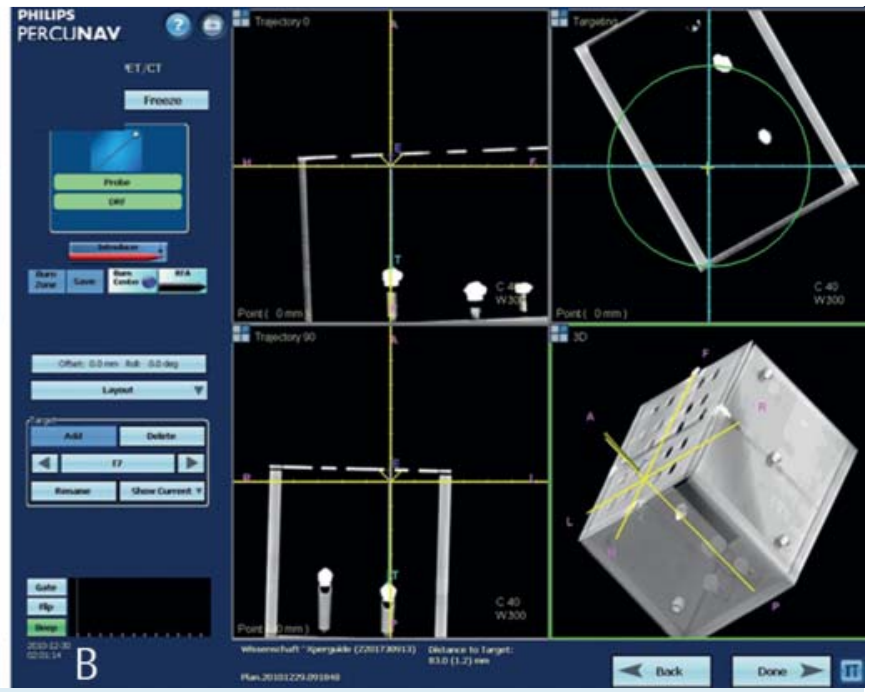

Abb. 2 Bildschirmfoto von Philips PercuNav während der Punktion. Die Plexiglas-Box und die Ziele werden in einer multiplanaren Ansicht angezeigt, die die 3 Hauptebenen und das 3D-Volumen-Rendering auf der unteren rechten Seite eines jeden Screenshots wiedergibt. Auf der linken Seite des Bildschirms sind die Icons erkennbar, die dem Anwender erlauben, innerhalb des Datensatzes zu navigieren und Messungen durchzuführen. Am Screenshot auf der linken Seite $\mathbf{A}$ wird die tatsächliche Position der Sondenspitze durch das gelbe Fadenkreuz dargestellt. Der geplante Pfad entspricht dem blauen Pfeil $(\leftarrow)$. Drei Kreuze sind sichtbar, die der Nadelspitze $(\hookrightarrow)$, dem Eintrittspunkt (<) und dem Zielpunkt (durchsichtiger Pfeil) entsprechen. Die 3 Kreuze sollten überlagert werden, um die optimale Position für die Punktion zu erreichen. Der Screenshot rechts B zeigt die optimale Ausrichtung der Sonde entlang des geplanten Punktionspfades.
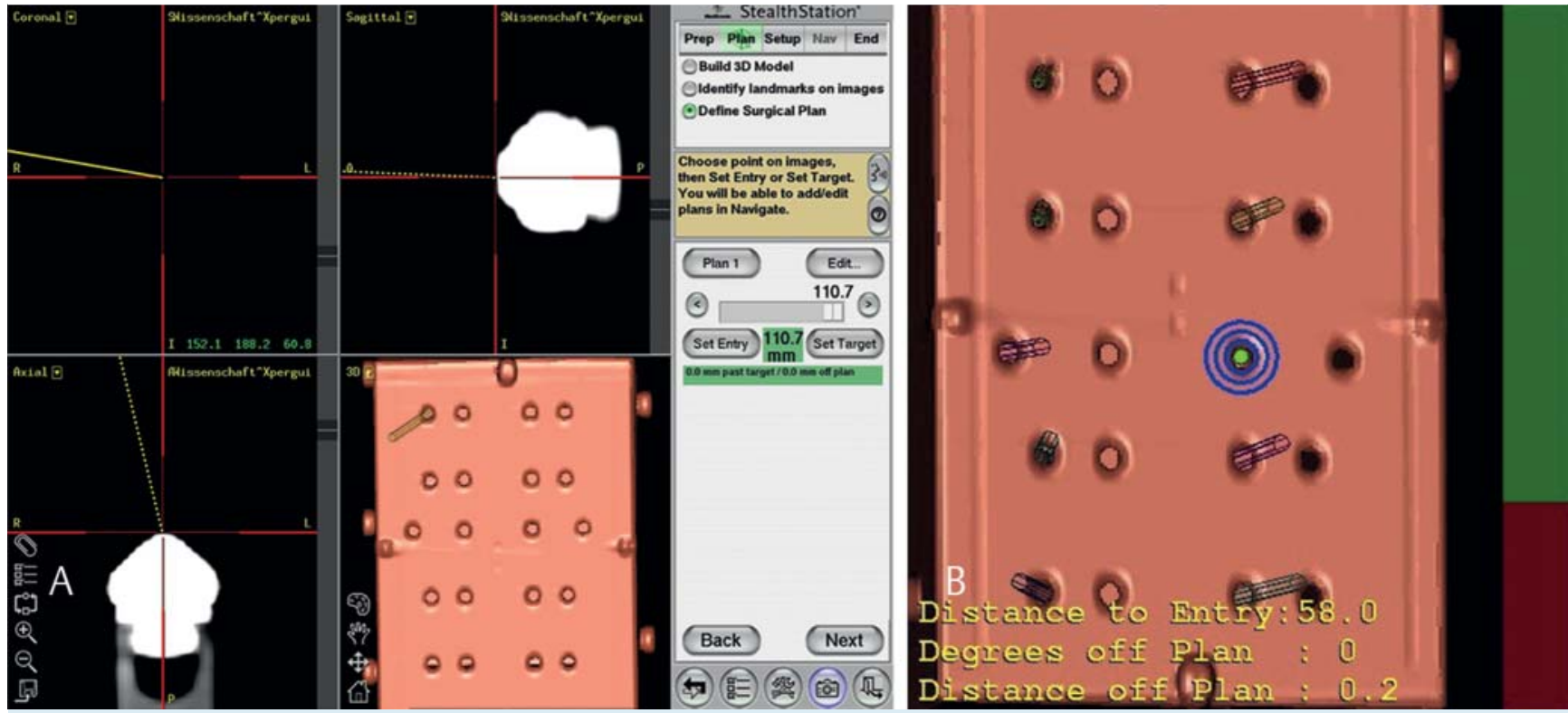

Fig. 3 Screenshot during the planning of a puncture pathway using Medtronic AxiEM. The Stealth Station navigation system enables reconstruction of multiplanar cross sections A. From upper left to lower right, coronal, sagittal, and axial views and a $3 \mathrm{D}$ rendering of the image data are depicted. The views show the definition of the target at the tip of the cone. The yellow path reflects the planned trajectory for needle insertion, with the target point on the tip of the marker. The display on the right side of the screenshot indicates the length of the planned trajectory in $\mathrm{mm}$. Image B represents the probe's eye view. The distance to the target, the distance off plan, and the degrees off plan are displayed. The concentric circles indicate an ideal alignment of the aiming device and the probe according to the planned path.
Abb. 3 Screenshot bei der Planung eines Punktionspfades mit Medtronic AXIEM. Das Stealth-Station Navigationssystem ermöglicht die Rekonstruktion multiplanarer Ansichten A. Von links oben nach rechts unten sind die koronale, sagittale und axiale Ansicht und ein 3D-Rendering der Bilddaten dargestellt. Die Ansichten zeigen die Definition des Ziels an der Spitze des Kegels. Der gelbe Weg spiegelt die geplante Trajektorie für den Stichkanal, mit dem Zielpunkt an der Spitze des Markers. Die Anzeige auf der rechten Seite des Bildschirms zeigt die Länge der geplanten Trajektorie in mm. Bild $\mathbf{B}$ zeigt die Ansicht in Richtung des geplanten Pfades. Der Abstand zu dem Ziel, die laterale Abweichung vom Plan und die Winkelabweichung vom Plan werden angezeigt. Die konzentrischen Kreise zeigen eine ideale Ausrichtung der Zielvorrichtung und der Sonde entlang des geplanten Pfads. 


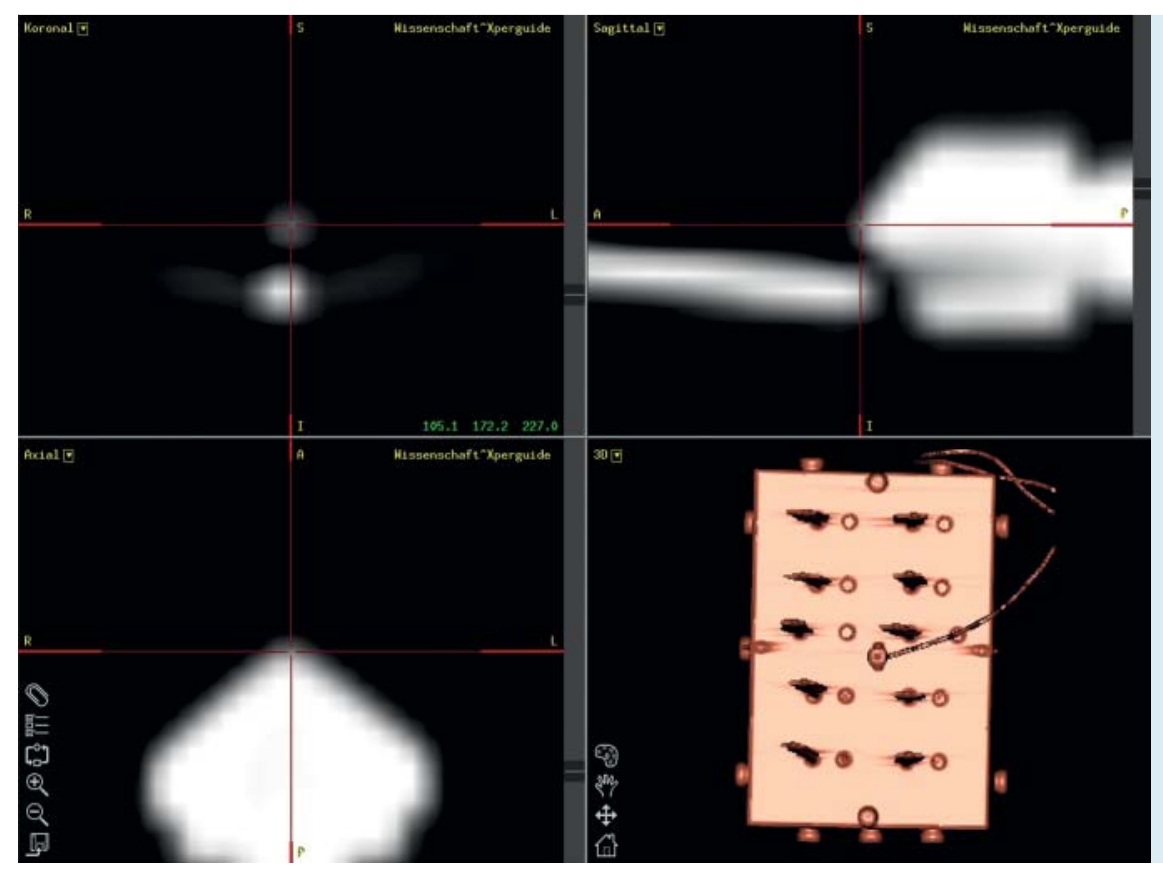

Fig. 4 The evaluation of needle positioning accuracy using the Medtronic Stealth Station Treon is performed using the control CT dataset by positioning the crosshairs in all three planes directly onto the actual needle entry point and by positioning the crosshairs onto the tip of the cone and the tip of the needle. The coordinates of all points, which are visible in the left upper quadrant of the image, are then transferred to an excel spreadsheet for calculation of the Euclidean distance and the lateral positioning error.

Abb. 4 Die Auswertung der Genauigkeit der Nadelpositionierung unter Verwendung der Medtronic Stealth Station Treon erfolgt am Kontroll-CT-Datensatz, indem ein Fadenkreuz direkt in allen 3 Ebenen auf dem aktuell vorliegenden Nadeleintrittspunkt. Ebenso wird ein Fadenkreuz auf die Spitze der Zielstruktur und auf die Spitze der Nadel gelegt. Die Koordinaten dieser Punkte, die im linken oberen Quadranten der Abbildung angegeben sind, werden in ein Excel Sheet übertragen, um den euklidischen Abstand und den lateralen Positionsfehler zu berechnen.

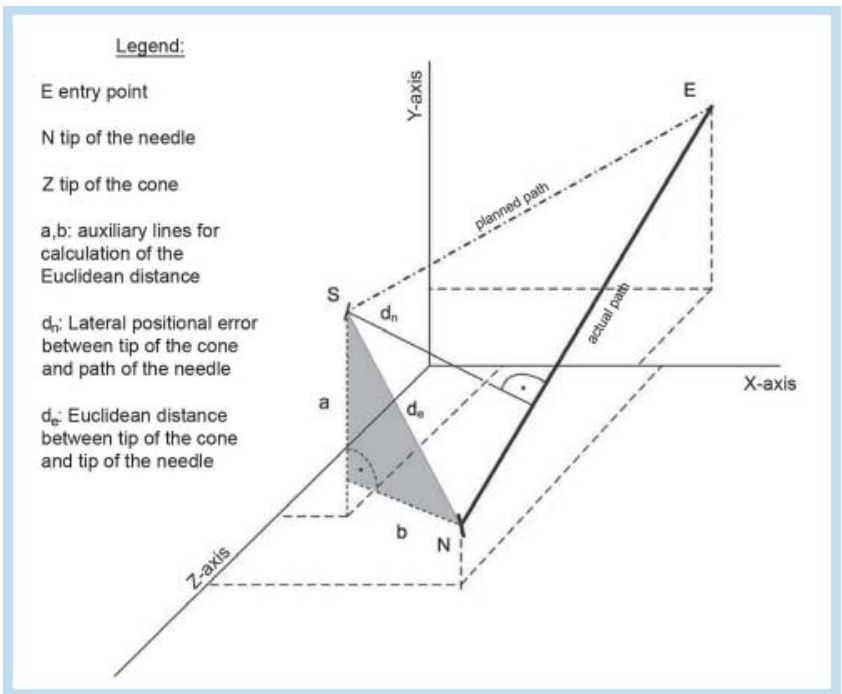

Fig. 5 The Euclidean distance is calculated using the coordinates of the actual position of the needle tip and the target point. The Euclidean distance indicates a deviation in the direction of the needle placement.

Abb.5 Der euklidische Abstand wird über die Koordinaten der tatsächlichen Position der Nadelspitze und des Zielpunktes berechnet. Der euklidische Abstand gibt einen Hinweis darauf, inwieweit es zu einer Abweichung von der geplanten Richtung der Punktion gekommen ist.

\section{Statistical Analysis}

Data were evaluated using PASW 18 (SPSS Inc., Chicago, Illinois, USA). The double-sided t-test was used to evaluate significant differences in puncture accuracy. A Kolmogorov-Smirnov Test was performed to ensure a normal distribution, and a Levene's test was performed for equality of variances. A p-value of less than 0.05 was considered statistically significant.

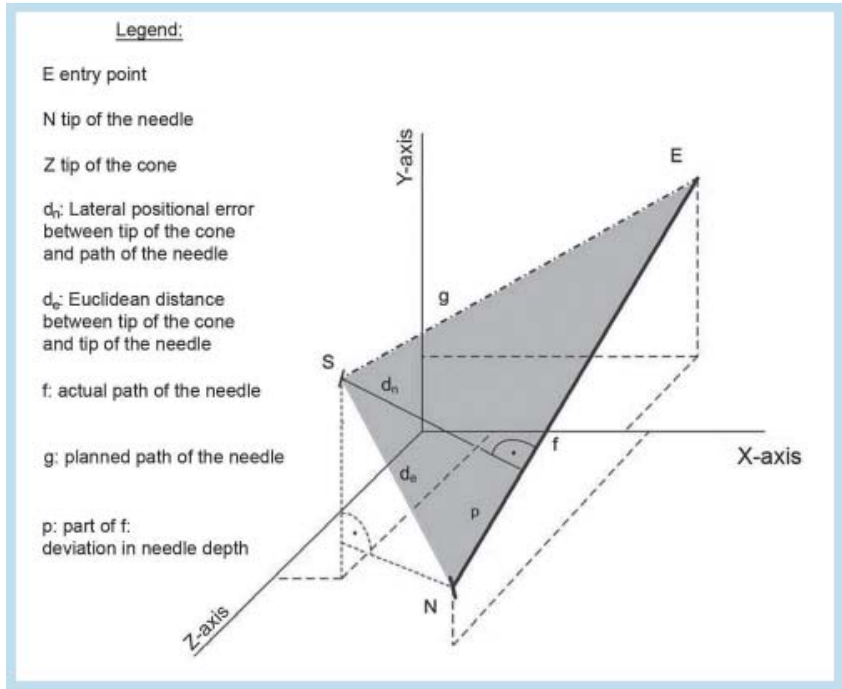

Fig. 6 A triangle has three sides, which are defined as the distance between the needle entry point and the tip of the needle, the planned needle path between the needle entry point and the target point, and the calculated Euclidean distance between target point and actual position of the tip of the needle. The height of the triangle corresponds to the lateral positioning error.

Abb. 6 Ein Dreieck wird über 3 Seiten definiert, und zwar über den eigentlichen Verlauf der Punktion zwischen Einstichstelle und Nadelspitze, dem geplanten Verlauf der Punktion zwischen Einstichstelle und Zielpunkt und der berechneten, euklidischen Distanz zwischen dem Zielpunkt und der tatsächlichen Position der Nadelspitze. Die Höhe dieses Dreiecks entspricht dem gesuchten, lateralen Positionsfehler.

\section{Results}

$\nabla$

In total, 480 punctures were performed manually: 80 punctures with 1,3 , and $5 \mathrm{~mm}$ slice thickness for each of the two navigation systems. 
Using the Philips PercuNav, the accomplished Euclidean distances were $4.42 \pm 1.33 \mathrm{~mm}, 4.26 \pm 1.32 \mathrm{~mm}$, and $4.46 \pm 1.56 \mathrm{~mm}$ at a slice thickness of 1,3 , and $5 \mathrm{~mm}$, respectively. The mean lateral positional errors were $3.84 \pm 1.59 \mathrm{~mm}, 3.84 \pm 1.43 \mathrm{~mm}$, and $3.81 \pm$ $1.71 \mathrm{~mm}$, respectively.

Using the Medtronic Stealth Station AxiEM, the Euclidean distances were $3.86 \pm 2.28 \mathrm{~mm}, 3.74 \pm 2.1 \mathrm{~mm}$, and $4.81 \pm 2.07 \mathrm{~mm}$ at a slice thickness of 1,3 , and $5 \mathrm{~mm}$, respectively. The mean lateral positional errors were $3.29 \pm 1.52 \mathrm{~mm}, 3.16 \pm 1.52 \mathrm{~mm}$, and $3.93 \pm$ $1.68 \mathrm{~mm}$, respectively.

The t-test for comparison of puncture accuracy using the Philips PercuNav with CT data sets of 1,3 , and $5 \mathrm{~mm}$ slice thickness revealed no significant difference in targeting accuracy. For manually guided punctures using the Medtronic Stealth Station AxiEM, the results using CT data sets with $1 \mathrm{~mm}$ slice thickness were significantly more accurate compared to the $5 \mathrm{~mm}$ CT data sets regarding the Euclidean distance, with $3.86 \pm 2.28 \mathrm{~mm}$ vs. $4.81 \pm 2.07 \mathrm{~mm}$, respectively $(\mathrm{p}<0.006)$, and regarding the lateral positional error, with $3.29 \pm 1.52 \mathrm{~mm}$ vs. $3.93 \pm 1.68 \mathrm{~mm}$, respectively $(\mathrm{p}<0.012)$. The results with $3 \mathrm{~mm}$ slice thickness were more accurate compared to $5 \mathrm{~mm}$ regarding the Euclidean distance, with $3.74 \pm 2.1 \mathrm{~mm}$ vs. $4.81 \pm 2.07 \mathrm{~mm}$, respectively $(\mathrm{p}<0.001)$, and regarding the lateral positional error, with $3.16 \pm 1.52 \mathrm{~mm}$ vs. $3.93 \pm 1.68 \mathrm{~mm}$, respectively ( $p<0.003$ ). Results for the Philips PercuNav and the Medtronic Stealth Station AxiEM did not reveal significant differences in accuracy when comparing CT data sets with $1 \mathrm{~mm}$ slice thickness ( $p<0.059$ ). With the $3 \mathrm{~mm}$ CT data sets, the lateral positional error showed significantly better results for the Medtronic Stealth Station AxiEM, with $3.16 \pm 1.52 \mathrm{~mm}$ vs. $3.84 \pm 1.43 \mathrm{~mm}(\mathrm{p}<0.004)$, while the $5 \mathrm{~mm}$ slice thickness did not reveal significant differences in accuracy ( $\bullet$ Table 1$)$.

\section{Discussion}

$\nabla$

Accuracy and safety are crucial issues when implementing a tracking system for puncture guidance in clinical routine. In order to allow for a wide range of applications, the navigation system requires a high standard of accuracy, reliability, and reproducibility. Both optical and electromagnetic navigation systems allow for accurate and reliable puncture planning, while their potential roles differ according to the requirements. Optical navigation systems such as the Medtronic Stealth Station Treon Plus are used in daily clinical routine and may be combined with targeting devices to facilitate minimal invasive punctures, as for the radiofrequency ablation of liver tumors [9]. The setup includes two or more fixed cameras in combination with dedicated active and passive fiducial markers. While passive markers are usually spheres which need additional illumination from the camera, active markers are infrared light emitting diodes. Optical tracking systems typically offer an in vitro accuracy of $0.2 \mathrm{~mm}$ for position and $0.4^{\circ}$ for orientation [10].

Electromagnetic navigation systems have already shown great potential for enabling a more flexible and easy handling of puncture probes $[3,4]$. The PercuNav was used for puncture planning and radiofrequency ablation $[11,12]$. The Medtronic Stealth Station AxiEM was used for pediatric neuroendoscopic interventions such as image-guided cerebrospinal fluid shunt placement $[13,14]$ and minimally invasive endoscopic transnasal approach to the craniovertebral junction in pediatric patients [15]. Electromagnetic tracking systems consist of a field generator, which creates an electromagnetic field, while sensors that measure the
Table 1 Accuracy of both Medtronic AxiEM (A) and Philips PercuNav (C) in comparison to the previously reported results of our group (B) by Stoffner et al. using an optical navigation system and the identical phantom [10]. The mean values, minimum and maximum values, and standard deviations for the Euclidean distances (DE) and normal distances (DN) between the target and the biopsy needle after manually $(\mathrm{M})$ guided puncture in $\mathrm{mm}$ are given for Medtronic AxiEM (MEM) and Philips PercuNav (TRX) for CT data sets with 1 , 3 , and $5 \mathrm{~mm}$ slice thickness.

Tab. 1 Genauigkeit von Medtronic AXiEM (A) und Philips PercuNAv (C) im Vergleich zu den früher publizierten Ergebnissen unserer Arbeitsgruppe (B) von Stoffner et al. unter Verwendung eines optischen Navigationssystems und desselben Phantoms [10]. Die Mittelwerte, Minimalwerte und Maximalwerte sowie die Standardabweichung sind angegeben für die Euklidischen Abstände (DE) und die mittleren seitlichen Positionsfehler (DN) zwischen der Zielstruktur und der Punktionsnadel. Die Punktionen wurden manuell geführt (M). Die Ergebnisse für Medtronic AxiEM (MEM) und Philips PercuNav (TRX) sind in mm angegeben, unter Berücksichtigung der CT-Datensätze mit 1,3 und $5 \mathrm{~mm}$ Schichtdicke.

\begin{tabular}{|c|c|c|c|}
\hline \multicolumn{4}{|l|}{ A AxiEM } \\
\hline & $1 \mathrm{~mm}$ & $3 \mathrm{~mm}$ & $5 \mathrm{~mm}$ \\
\hline DE mean & 3.855 & 3.744 & 4.813 \\
\hline DE min. & 1.075 & 1.050 & 1.342 \\
\hline DE max. & 15.775 & 10.327 & 10.467 \\
\hline DE standard dev. & 2.275 & 2.101 & 2.065 \\
\hline DN mean & 3.291 & 3.157 & 3.934 \\
\hline DN min. & 0.259 & 0.441 & 0.110 \\
\hline DN max. & 9.871 & 8.428 & 8.757 \\
\hline DN standard dev. & 1.517 & 1.522 & 1.683 \\
\hline \multicolumn{4}{|c|}{ B Stealth Station Treon } \\
\hline & $1 \mathrm{~mm}$ & $3 \mathrm{~mm}$ & $5 \mathrm{~mm}$ \\
\hline DE mean & 1.94 & 2.2 & 2.74 \\
\hline DE min. & 0 & 0.63 & 0.31 \\
\hline DE max. & 4.79 & 5.54 & 6.84 \\
\hline DE standard dev. & 0.912 & 1136.00 & 1.166 \\
\hline DN mean & 1.64 & 1.84 & 2.48 \\
\hline DN min. & 0 & 0.09 & 0.12 \\
\hline DN max. & 4.57 & 5.09 & 6.64 \\
\hline DN standard dev. & 0.919 & 1.189 & 1.196 \\
\hline \multicolumn{4}{|l|}{ C PercuNav } \\
\hline & $1 \mathrm{~mm}$ & $3 \mathrm{~mm}$ & $5 \mathrm{~mm}$ \\
\hline DE mean & 4.417 & 4.263 & 4.457 \\
\hline DE min. & 2.441 & 2.062 & 2.095 \\
\hline DE max. & 8.699 & 7.974 & 9.217 \\
\hline DE standard dev. & 1.333 & 1.322 & 1.562 \\
\hline DN mean & 3.759 & 3.840 & 3.807 \\
\hline DN min. & 1.272 & 1.029 & 0.496 \\
\hline DN max. & 8.699 & 7.723 & 8.103 \\
\hline DN standard dev. & 1.594 & 1.425 & 1.708 \\
\hline
\end{tabular}

magnetic field strength are registered in their position and orientation to the field generator. The coils are oriented in a tetrahedral configuration. The small size of such tracking sensors enables integration into various tools including needles. However, the electromagnetic field decreases with distance from the field generator, limiting its range. In addition, field distortions by metallic or electronic components, such as imaging devices, must be considered during positioning of patient and instruments [10, 16]. This can be avoided by using metals with low electrical conductivity, such as stainless steel or titanium [17]. Electromagnetic navigation systems provide a technical accuracy of $1.5 \mathrm{~mm}$ for position and $0.4^{\circ}$ for orientation [18]. Electromagnetic tracking devices do not need a direct line of sight and, due to their small size, can be located close to the point of interest, so tracking error for a specific point may be even lower than with optical tracking. 
In addition, bendable instruments may be used. The difference is that electromagnetic tracking calculates position from minute current variations, which are derived from a change in the magnetic flux received in a copper coil. These coils are fixed in remote position and produce a varied current according to their orientation in the field. Trigonometric calculations then form the basis in order to triangulate all 6 degrees of freedom: the $\mathrm{x}, \mathrm{y}$, and $\mathrm{z}$ positions, as well as yaw, pitch, and roll. Calculation of the position and orientation of the sensor relative to the transmitter is therefore based on real-time electrical measurement [10]. In addition, the probes for electromagnetic tracking are light and small.

Our study demonstrates successful registration, planning, and needle placement in a phantom using electromagnetic navigation devices. The Medtronic AxiEM showed significantly better results than the Philips PercuNav regarding Euclidean distance and lateral positional error for punctures with 1 and $3 \mathrm{~mm}$ slice thickness as compared to $5 \mathrm{~mm}$ slice thickness. The differences of the mean value were $0.56 \mathrm{~mm}$ and $0.52 \mathrm{~mm}$ for the Euclidean distance and 0.55 and $0.68 \mathrm{~mm}$ for the lateral positional error for 1 and $3 \mathrm{~mm}$ slice thickness, respectively. Regarding the lateral positional error, a significantly better result was only observed with data sets with $3 \mathrm{~mm}$ slice thickness. The consistency of the gelatin within the phantom may pose a limiting factor to accuracy, as it may not prevent the positioned wires from slipping slightly while the phantom is moved. Therefore, the lateral positional error between the target and the needle axis may be the most reliable indicator of accuracy.

The clinical acceptance and utility of each navigation system is mainly dependent on the increase in accuracy in comparison to CT-guided freehand techniques. Even if the differences between the two electromagnetic guidance systems observed in our study may not transfer in a clinically relevant difference between the two systems, our results indicate the usefulness of both guidance systems to allow for highly precise interventional procedures.

In rigid phantom studies, electromagnetic navigation systems reached accuracies of up to $1 \mathrm{~mm}$ [19]. However, in contrast to the phantom study, registration errors because of patient motion and organ shift due to respiratory motion are key points in the clinical setting.

Mallmann et al. assessed the patient movement in interventional procedures with electromagnetic detection comparing a conventional fixation device to the use of a vacuum mattress [20]. Seventeen patients were evaluated at rest and after a repositioning maneuver. When using a vacuum mattress, the mean observed patient movement was $4.3 \pm 2.8 \mathrm{~mm}$ at rest and $17.1 \pm 15.7 \mathrm{~mm}$ without fixation. Total patient movement was less when using the fixation device, with a mean value of $4.6 \pm 2.5 \mathrm{~mm}$, in comparison to $27.8 \pm 19.6 \mathrm{~mm}$ in a setting without patient fixation. Taking into consideration these results, the patient fixation is a limiting factor for the accuracy of interventional procedures. Therefore, the differences in accuracy observed in our group are not generally of relevance in a clinical setting. However, the influence on the biopsy accuracy depends very much on the specific clinical setting.

CT-guided stereotactic targeting accuracy data of osteoid osteoma were reported in 16 patients with mean lateral targeting errors of $2.6 \pm 1.7 \mathrm{~mm}$ at the needle entry and $1.9 \pm 1.2 \mathrm{~mm}$ at the needle tip, with mean angular errors of $2^{\circ} \pm 1.3^{\circ}$ [21]. In this study, an optical navigation system and an aiming device were used in combination with a vacuum mattress for patient immobilization. The same navigation system and aiming device used in another study evaluating the accuracy and diagnostic yield of
CT-guided stereotactic liver biopsy reported a median lateral error of $2.5 \mathrm{~mm}$ (range: $0-6.5 \mathrm{~mm}$ ) at the needle entry point and $3.2 \mathrm{~mm}$ (range: $0.01-9.4 \mathrm{~mm}$ ) at the needle tip, with a median angular error of $1.06^{\circ}$ (range: $0-6.64^{\circ}$ ) in 46 liver biopsies [22]. To compensate for respiratory motion artifacts, respiratory triggering was performed by disconnection of the endotracheal tube during general anesthesia.

In the near future, robots with active control may compensate for respiratory artifacts by controlled movement of the guidance unit.

The use of different target and phantom designs together with varying imaging protocols prevent a direct comparison of accuracies reported by other groups. The size of the targets strongly influences the target definition error. Small targets especially may lead to increased target definition errors due to partial volume phenomenon in the surrounding voxels. Meyer et al. published data using the Cappa IRADEMT electromagnetic navigation device for 76 punctures in a phantom and 12 punctures in patients [23]. The mean deviation regarding punctures was $2.3 \pm 0.9 \mathrm{~mm}$ using the phantom and $5.4 \pm 1.9 \mathrm{~mm}$ in the patients. Appelbaum et al. used a similar electromagnetic deviation device for accuracy analysis in a phantom study, showing deviations of $2.6 \pm 1.1 \mathrm{~mm}$ up to $4 \pm 1 \mathrm{~mm}$ in 117 punctures using planning data sets with $1 \mathrm{~mm}$ slice thickness [24]. Krücker et al. described the use of an electromagnetic navigation device for planning of sonographically guided radiofrequency ablation of liver lesions in 20 patients [25]. The mean deviation between the registered position of the needle and the actual position is given as $5.8 \pm 2.6 \mathrm{~mm}$. MeierMeitinger et al. proved the accuracy of the Cappa IRAD navigation system in combination with an optical tracking system performing 60 punctures in a spine phantom and 15 in patients using CT data sets for planning [26]. The phantom biopsies resulted in an accuracy of $1.1 \pm 0.4 \mathrm{~mm}$.

Our group used the identical phantom and aiming device to perform 300 punctures with the Medtronic Stealth Station Treon Plus optical navigation system [8]. Mean Euclidean distances of $1.94 \pm 0.912,2.2 \pm 1.136$, and $2.74 \pm 1.166 \mathrm{~mm}$ were reached, for slice thicknesses of 1,3 , and $5 \mathrm{~mm}$, respectively. The mean lateral positional errors were $1.64 \pm 0.919,1.84 \pm 1.189$, and $2.48 \pm 1.196 \mathrm{~mm}$, respectively. Evaluation of the puncture accuracy revealed sufficient accuracy using a $3 \mathrm{~mm}$ slice thickness for planning CT data, which is in accordance with our findings.

When comparing accuracy results of manually guided punctures using the Philips PercuNav, no significant differences can be observed according to the data sets with different slice thickness. In contrast, puncture accuracy of manually guided punctures with the Medtronic AxiEM showed significantly more accurate results for Euclidean and lateral positional error using data sets with $1 \mathrm{~mm}$ slice thickness than when using data sets with $5 \mathrm{~mm}$ slice thickness. Results using data sets with $3 \mathrm{~mm}$ slice thickness were more accurate than when using data sets with $5 \mathrm{~mm}$ slice thickness, while no difference was observed in the groups with 1 and $3 \mathrm{~mm}$ slice thickness. The Medtronic AxiEM showed slight advantages over the Philips PercuNav for punctures using data sets with 1 and $3 \mathrm{~mm}$ slice thickness. As there is no significant difference between the results using either data sets with 1 or $3 \mathrm{~mm}$ slice thickness, planning CT should be performed using $3 \mathrm{~mm}$ slice thickness as a measure of radiation protection.

Different navigation systems are used according to the required procedure, and accuracy may vary [8]. The requirements for clinical feasibility of electromagnetically based navigation systems include highly accurate results of needle placement, as well as 
reproducibility, easy handling, and stability of the electromagnetic field, which can be influenced by metallic objects. By placing a dynamic reference frame onto the patient, patients may be moved during the intervention. However, manual manipulation is limited if the patient has to be fixed in a certain position. Ventilation of the patient results in organ position changes. Breathing control is a central point in achieving high puncture accuracy [27]. Disconnection from the laryngeal tube for some seconds after preoxygenation can assist in achieving highly accurate puncture results in organs. However, respiratory motion compensation, patient motion error, and organ shift remain difficulties in clinical practice $[28,29]$.

Most importantly, electromagnetic navigation devices do not require the instruments to be within sight of the navigation system, which allows for a more flexible arrangement and assures a sterile environment in narrow operation fields. Electromagnetically guided navigation systems may also be used for tracking of the tip of angiographic catheters. Moreover, radiation exposure to the patient and operators may be reduced when using navigation devices, as the need for control CT may be reduced. Electromagnetic navigation devices have already shown potential for reducing the radiation burden during interventional procedures by reducing the need for repeated control imaging. However, the data on reduction of radiation exposure by the use of electromagnetic navigation devices mainly refer to studies evaluating the use of such navigation systems during cardiac interventions. [30, 31].

However, electromagnetic navigation devices can influence pacemakers and cochlea implants, thus preventing their use in patients with these implants. Furthermore, instruments are connected to the navigation system by wires, which can be more difficult to handle when many needles are placed. The electromagnetic navigation field is also influenced by external magnetic fields and ferromagnetic items [32, 33], which causes problems when using the navigation system in combination with a ferromagnetic aiming device. An important issue is the limited working space that is dependent on the electromagnetic field strength, which can be influenced by the positioning and orientation of generator and receiver [34].

\section{Conclusion}

\section{$\nabla$}

Our results of a phantom puncture series show that accurate CTguided punctures can be achieved using electromagnetic guidance. Both electromagnetic navigation systems used in this study have shown highly accurate puncture results when using CT data sets with $3 \mathrm{~mm}$ slice thickness. The Medtronic Stealth Station AxiEM provided even more accurate results than the Philips PercuNav, yielding highly precise results when performing CT with $3 \mathrm{~mm}$ slice thickness. However, due to possible interference with external magnetic fields and metal objects, incorrect position sensing may occur. Further studies are needed to clearly define the operating range in clinical routine. In contrast to the phantom study, patient movement including respiratory artifacts must be taken into account and compensated for in the clinical setting.

\section{References}

1 Schullian P, Widmann G, Lang TB et al. Accuracy and diagnostic yield of CT-guided stereotactic liver biopsy of primary and secondary liver tumors. Comput Aided Surg 2011; 16: 181-187
2 Bale R, Widmann G, Haidu M. Stereotactic radiofrequency ablation. Cardiovasc Intervent Radiol 2011; 34: 852 - 856

3 Meyer BC, Wolf KJ, Wacker FK. Flat-detector CT-based electromagnetic navigation. Radiologe 2009; 49: 856-861

4 Penzkofer T, Isfort P, Bruners P et al. Robot arm based flat panel CTguided electromagnetic tracked spine interventions: phantom and animal model experiments. Eur Radiol 2010; 20: 2656 - 2662

5 Lionberger DR, Weise J, Ho DM et al. How does electromagnetic navigation stack up against infrared navigation in minimally invasive total knee arthropasties? J Arthropl 2008; 23: 573-580

6 Harrison SE, Shooman D, Grundy PL. A prospective study of the safety and efficacy of frameless pinless electromagnetic image-guided puncture of cerebral lesions. Neurosurgery 2012; 70: 29-33

7 Kruecker J, Viswanathan A, Borgert J et al. An electromagnetically tracked laparoscopic ultrasound for multi-modality minimally invasive surgery. Proceedings of Int'l Congress on Computer Assisted Radiology and Surgery (CARS).746 - 751

8 Stoffner R, Augschöll C, Widmann G et al. Accuracy and feasibility of frameless stereotactic and robot-assisted CT-based puncture in interventional radiology: a comparative phantom study. Fortschr Röntgenstr 2009; 181: $851-858$

9 Bale R, Widmann G, Schullian P et al. Percutaneous stereotactic radiofrequency ablation of colorectal liver metastases. Eur Radiol 2012; 22: 930-937

10 Haidegger T, Fenyvesi G, Sirokai B et al. Towards unified electromagnetic tracking system assessment statistic errors. Conf Proc IEEE Eng Med Biol Soc 2011; DOI: 10.1109/IEMBS.2011.6090539

11 Venkatesan AM, Kadoury S, Abi-Jaoudeh $N$ et al. Real-time FDG PET guidance during biopsies and radiofrequency ablation using multimodality fusion with electromagnetic navigation. Radiology 2011; 260: $848-856$

12 Verma S, Bhavsar AS, Donovan J. MR imaging-guided prostate biopsy techniques. Magn Reson Imaging Clin N Am 2014; 22: 135-144

13 Levitt MR, O'Neill BR, Ishak GE et al. Image-guided cerebrospinal fluid shunting in children: catheter accuracy and shunt survival. J Neurosurg Pediatrics 2012; 10: 112-117

14 Clark S, Sangra M, Hayhurst C et al. The use of noninvasive electromagnetic neuronavigation for slit ventricle syndrome and complex hydrocephalus in a pediatric population. J Neurosurg Pediatrics 2009; 2: $430-434$

15 Tan SH, Ganesan D, Prepageran $N$ et al. A minimally invasive endoscopic transnasal approach to the craniovertebral junction in the paediatric population. Eur Arch Otorhinolarnygol 2014; 271: 3101 - 3105

16 Yaniv Z, Wilson E, Lindisch E et al. Electromagnetic tracking in the clinical environment. Medical Physics 2009; Vol. 36, No. 3: 876-892

17 Wood BJ, Zhang H, Durrani A et al. Navigation with electromagnetic tracking for interventional radiology procedures: a feasibility study. J Vasc Interv Radiol 2005; 16: 493 - 505

18 Wiles AD, Thompson DG, Frantz DD. Accuracy assessment and interpretation for optical tracking systems. In: Galloway RL Jr Ed Proceedings of SPIE Medical Imaging 2004: Visualization, Image-Guided Procedures, and Display. $421-432$

19 Condino S, Ferrari V, Freschi $C$ et al. Electromagnetic navigation platform for endovascular surgery: how to develop sensorized catheters and guidewires. IndJMedRobot 2012; 8: $300-310$

20 Mallmann C, Wolf KJ, Wacker FK et al. Assessment of patient movement in interventional procedures using electromagnetic detection - comparison between conventional fixation and vacuum mattress. Fortschr Röntgenstr 2012; 184: 37-41

21 Widmann G, Schullian P, Fasser $M$ et al. CT-guided stereotactic targeting accuracy of osteoid osteoma. Int J Med Robot 2013; 9: 274-279

22 Schullian P, Widmann G, Lang TB et al. Accuracy and diagnostic yield of CT-guided stereotactic liver biopsy of primary and secondary liver tumors. Comput Aided Surg 2011; 16: 181-187

23 Meyer $B C$, Peter O, Nagel $M$ et al. Electromagnetic field-based navigation for percutaneous punctures on C-arm CT: experimental evaluation and clinical application. Eur Radiol 2008; 18: 2855-2864

24 Appelbaum L, Sosna J, Nissenbaum Y et al. Electromagnetic navigation system for CT-guided puncture of small lesions. Am J Roentgenol 2011; 196: 1194-1200

25 Krücker J, Xu S, Glossop N et al. Electromagnetic tracking for thermal ablation and puncture guidance: clinical evaluation of spatial accuracy. J Vasc Interv Radiol 2007; 18: 1141 - 1150

26 Meier-Meitinger M, Nagel M, Kalender W et al. Computer-assisted navigation system for interventional CT-guided procedures: results of 
phantom and clinical studies. Fortschr Röntgenstr 2008; 180: 310 317

27 Chen A, Pastis N, Furukawa B et al. The effect of respiratory motion on pulmonary nodule location during electromagnetic navigation bronchoscopy. Chest 2015; 147: 1275-1281

28 Widmann G, Schullian P, Haidu M et al. Respiratory motion control for stereotactic and robotic liver interventions. Int J Med Robot 2010; 6: $343-349$

29 Timinger H, Krueger S, Borgert J et al. Motion compensation for interventional navigation on 3D static roadmaps based on an affine model and gating. Phys Med Biol 2004; 49: 719-732

30 Thibault B, Andrade JG, Dubuc $M$ et al. Reducing radiation exposure during CRT implant procedures: early experience with a sensor-based navigation system. Pacing Clin Electrophysiol 2015; 38: 63-70
31 Malliet N, Andrade JG, Khairy P et al. Impact of a Novel Catheter Tracking System on Radiation Exposure during the Procedural Phases of Atrial Fibrillation and Flutter Ablation. Pacing Clin Electrophysiol 2015; 38: $784-790$

32 Nieminen JM, Kirsch SR. Eddy current detection and compensation. Patent US 7,957,925, Northern Digital Inc., June 2011

33 Frantz $D D$, Wiles $A D$, Leis SE et al. Accuracy assessment protocols for electromagnetic tracking systems. Physics in Medicine and Biology 2003; Vol. 48, No. 14: 2241 - 2251

34 Kettenbach J, Kara L, Toporek G et al. A robotic needle-positioning and guidance system for CT-guided puncture: Ex vivo results. Minim Invasive Ther Allied Technol 2014; 23: 271 - 278 